\title{
Tunable photoinduced carrier transport of a black phosphorus transistor with extended stability using a light-sensitized encapsulated layer
}

Po-Hsun Ho, ${ }^{\perp}$ Min-Ken Li,${ }^{\perp}$ Raman Sankar, Fu-Yu Shih, Yih-Ren Chang, Shao-Sian

Li, Wei-Hua Wang, Fang-Cheng Chou and Chun-Wei Chen*

${ }^{\perp}$ These authors contributed equally to this work

\section{Characterizations of Black phosphorus (BP)}

The bulk BP single crystals were grown via $\mathrm{SnI}_{4}$ chemical vapor transport (CVT) method in our lab, where high quality BP single crystal with a large size more than $0.7 \mathrm{~cm}$ was obtained as shown in Figure S1. The detailed synthesis processes of growing single-crystal BP is described in the section of experimental methods. The X-ray diffraction (XRD) of black phosphorus (Figure S2(a)) shows clear and sharp diffraction peaks corresponding to the black phosphorus compound, indicating the phase purity of the prepared material and the preferred crystalline orientation of ab-plane of (00L) diffraction peaks. As for the as-exfoliated few-layer BP, Raman spectroscopy was used to confirm the quality. The measured Raman peaks (Figure $\mathrm{S} 2(\mathrm{~b}))$ at $360,439,468 \mathrm{~cm}^{-1}$ are attributed to the $\mathrm{A}_{\mathrm{g}}^{1}, \mathrm{~B}_{2 \mathrm{~g}}, \mathrm{~A}_{\mathrm{g}}^{2}$ phonon modes in 
crystalline few-layer black phosphorus flakes, which matched well with the previous observations. $^{1}$

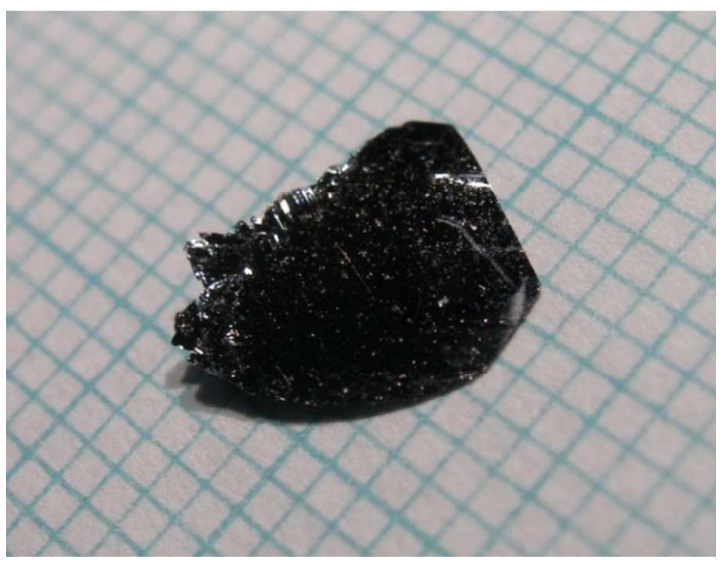

Figure S1 Optical image of as-synthesized BP single crystal

(a)

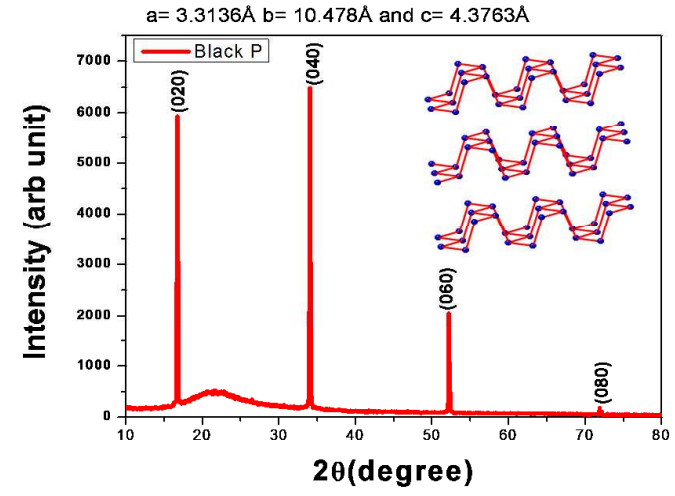

(b)

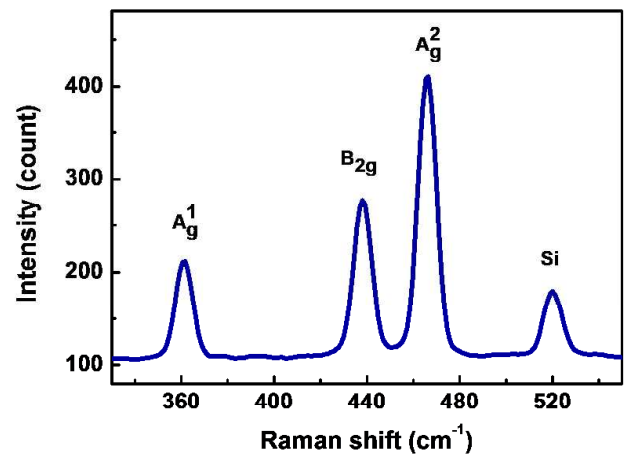

Figure S2 (a) X-ray diffraction spectrum of the as-grown BP single crystal with preferred (00L) peaks. (b) Raman spectrum of exfoliated few-layer BP on silica. 


\section{Synthesis of amorphous $\mathrm{TiO}_{\mathrm{x}}$}

The amorphous $\mathrm{TiO}_{\mathrm{x}}$ were synthesized using sol-gel process. In brief, 2-methoxyethanol $\left(\mathrm{CH}_{3} \mathrm{OCH}_{2} \mathrm{CH}_{2} \mathrm{OH}, \quad\right.$ Acros, 99+\%) and ethanolamine $\left(\mathrm{H}_{2} \mathrm{NCH}_{2} \mathrm{CH}_{2} \mathrm{OH}\right.$, Acros, 99\%) were first mixed in a three-necked flask, and titanium (IV) isopropoxide $\left(\mathrm{Ti}\left[\mathrm{OCH}\left(\mathrm{CH}_{3}\right)_{2}\right]_{4}\right.$, Acros, $\left.98+\%\right)$ was then injected after 10 minutes stirring. The mixture was kept at $80{ }^{\circ} \mathrm{C}$ for 1 hour for alcoholysis reaction, and then raised to $120{ }^{\circ} \mathrm{C}$ to enhance condensation reaction. The heating durations at $120{ }^{\circ} \mathrm{C}$ were lasted for 3, 6 and 9 hours to obtain $\mathrm{TiO}_{\mathrm{x}}$ with different $\mathrm{O} / \mathrm{Ti}$ ratios.

\section{Band structure of $\mathrm{TiO}_{\mathrm{x}}$}

In order to investigate the doping effect of $\mathrm{TiO}_{\mathrm{x}}$ on $\mathrm{BP}$ flake, it is necessary to define the energy diagram of $\mathrm{TiO}_{\mathrm{x}}$ in this study. The cyclic voltammetry (CV) and optical absorption measurements were used to determine the lowest unoccupied molecular orbital (LUMO) and the band gap of the $\mathrm{TiO}_{\mathrm{x}}$ film respectively. The CV experiment was performed in a three-electrode electrochemical cell by using an Autolab PGSTAT302N potentiostat/galvanostat. The $\mathrm{TiO}_{\mathrm{x}}$ film on platinum $(\mathrm{Pt})$ electrode was used as working electrode and the $\mathrm{Pt}$ wire and $\mathrm{Ag} / \mathrm{AgCl}$ electrode were used as counter and reference electrodes in saturated $\mathrm{KCl}$ solution, respectively. All the measurements were carried out at a sweep rate of $100 \mathrm{mV} / \mathrm{s}$ in the presence of $0.1 \mathrm{M}$ 
tetra- $n$-butylammoniumhexylfluphosphate $\left(\mathrm{TBAPF}_{6}\right)$ in anhydrous acetonitrile $(\mathrm{ACN})$ as an electrolyte. The onset of cyclic voltammogram (reference to $\mathrm{Ag} / \mathrm{AgCl}$ ) for the $\mathrm{TiO}_{\mathrm{x}}$ thin film was used to determine the LUMO level according the following Equation S1.

$\mathrm{E}^{\mathrm{LUMO}}=-\left(\mathrm{E}_{\mathrm{TiOx}}-\mathrm{E}_{\mathrm{F}_{\mathrm{C}} / \mathrm{F}_{\mathrm{C}}{ }^{+}}\right)-4.8 \mathrm{eV}$

The redox couple ferrocene/ferricenium ion $\left(\mathrm{Fc} / \mathrm{Fc}^{+}\right)$was used as a standard, according to the ferrocene value of $-4.8 \mathrm{eV}$ relative to the vacuum level. ${ }^{2}$ Hence, the LUMO level of $\mathrm{High}^{-\mathrm{TiO}_{\mathrm{x}}}$ is about $-4.2 \mathrm{eV}$. The absorption spectrum in Figure S3(a) suggests that the band gap of $\mathrm{TiO}_{\mathrm{x}}$ is about $3.3 \mathrm{eV}$ obtained from the Tauc plot $^{3}$ using the relation $\alpha h v \propto\left(h v-E_{g}\right)^{1 / 2}$, where $\alpha$ is the absorption coefficient, $h v$ is the photon energy, and $E_{g}$ is the optical gap. As a result, the band structure could be constructed by the energy of LOMO and band gap as shown in Figure S3(b). Figure S4 also showed the ideal schematic representation of the band alignment along the transport path for electrons and holes. 
(a)

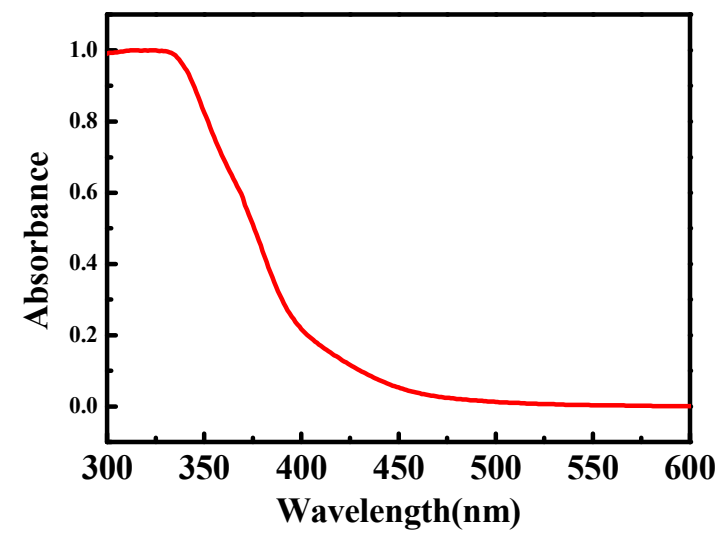

(b)

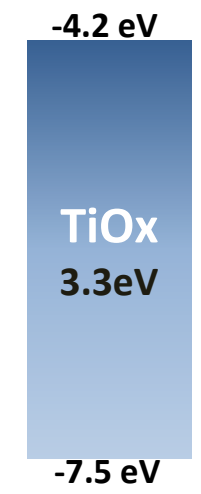

Figure $\mathbf{S 3}$ (a) UV-VIS absorption spectra of $\mathrm{TiO}_{\mathrm{x}}$. (b) Band structure of $\mathrm{TiO}_{\mathrm{x}}$.

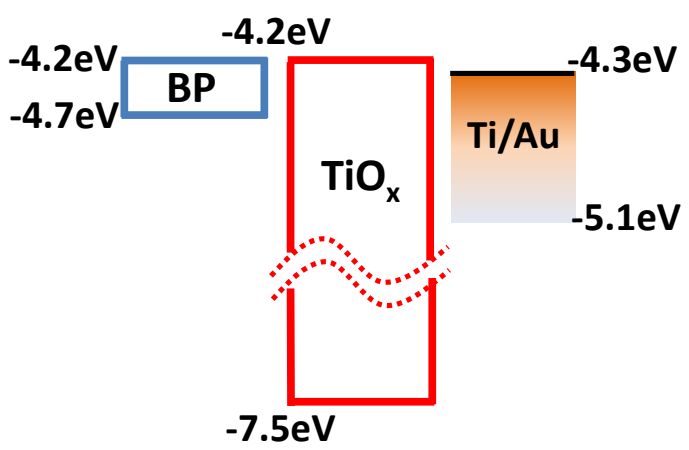

Figure S4. Schematic representation of the band alignment along the transport path for electrons and holes. The energy levels of BP and Ti/Au are obtained from Ref.22 and Ref.23 in the main manuscript respectively. Here, the enegy band diagram represents an idea case, where the possible formation of oxide layers at the surface of $\mathrm{BP}$ and Ti are not taken for account. 


\section{Fabrication process of $\mathrm{TiO}_{\mathrm{x}} / \mathrm{BP}$ transistor}

Few-layer black phosphorus flakes were mechanically exfoliated from bulk black phosphorus crystal using the Scotch tape method and transferred onto a heavily n-doped $300 \mathrm{~nm} \mathrm{SiO}_{2} / \mathrm{Si}$ wafer. The samples were then immediately brought into the glove box and $3 \mathrm{mg} / \mathrm{ml}$ solution $\mathrm{TiO}_{\mathrm{x}}$ was spin coated (5000rpm, 150s) onto the samples to prevent the black phosphorus flakes from degradation in ambient condition. The flakes were identified using optical microscopy and characterized by atomic force microscopy. A home-made shadow mask was used to defined the source-drain electrodes by thermal evaporation of $5 \mathrm{~nm} \mathrm{Ti} / 50 \mathrm{~nm} \mathrm{Au}$ contacts. No annealing process was performed after the deposition. The schematic diagram of the fabrication process is shown in Figure S5. Finally, the few-layered black phosphorus field-effect transistors were loaded into a probe station chamber (Linkem, HFS600E-P) and the electrical measurements were carried out by using the Keithley 2400 and 6487 source meters equipped with a 365nm LED (Mightex Inc.). 
(a)

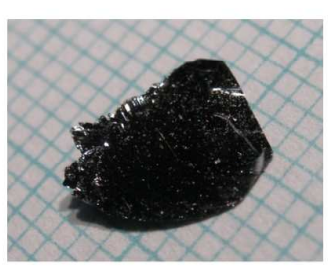

(b)

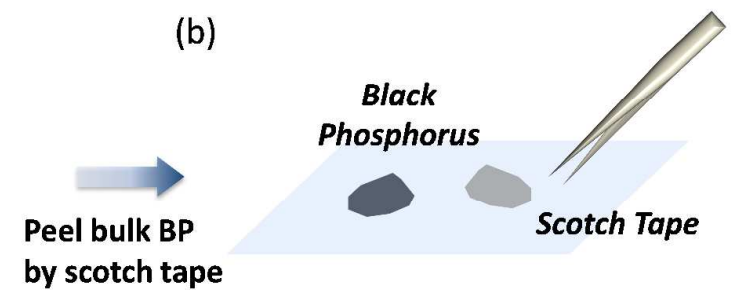

(c)

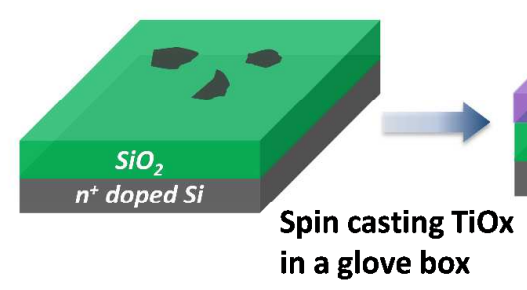

(d)

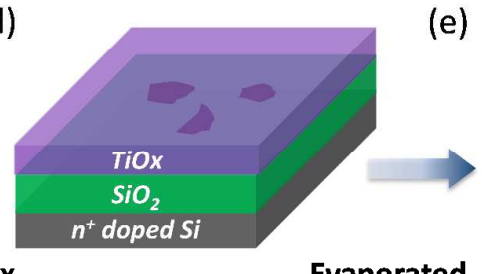

Evaporated source-drain electrodes

Figure S5: Fabrication flow chart of $\mathrm{a}_{\mathrm{TiO}} / \mathrm{BP}$ transistor

\section{I-V characteristic of post-coated $\mathrm{TiO}_{\mathrm{x}} / \mathrm{BP}$ transistor}

In order to compare with the performance of pre-coated $\mathrm{TiO}_{\mathrm{x}}$ device as described in manuscript, a post-coated $\mathrm{TiO}_{\mathrm{x}} / \mathrm{BP}$ transistor was fabricated by depositing $\mathrm{TiO}_{\mathrm{x}}$ film after the source-drain electrode were fabricated as shown in Figure S6 (a). Because the exfoliated BP would be rapidly degraded after being cleaved, oxidized particles were still formed on the surface of BP during the process of fabricating the metal electrodes, which acted as electron traps in the conduction channel of BP. When the device is under UV illumination, there is no obvious change in the current evolution of the electron branch as seen in the pre-coated $\mathrm{TiO}_{\mathrm{x}} / \mathrm{BP}$ FET device discussed in the main manuscript. The effect of photoinduced doping is much weaker in the post-coated $\mathrm{TiO}_{\mathrm{x}} / \mathrm{BP}$ FET device because of inevitable oxidation of $\mathrm{BP}$ surface. As a 
result, the deposition of a pre-coated $\mathrm{TiO}_{\mathrm{x}}$ film on a BP FET device has the unique advantage of being as an encapsulated layer and as a photodoping layer.

(a)

(b)
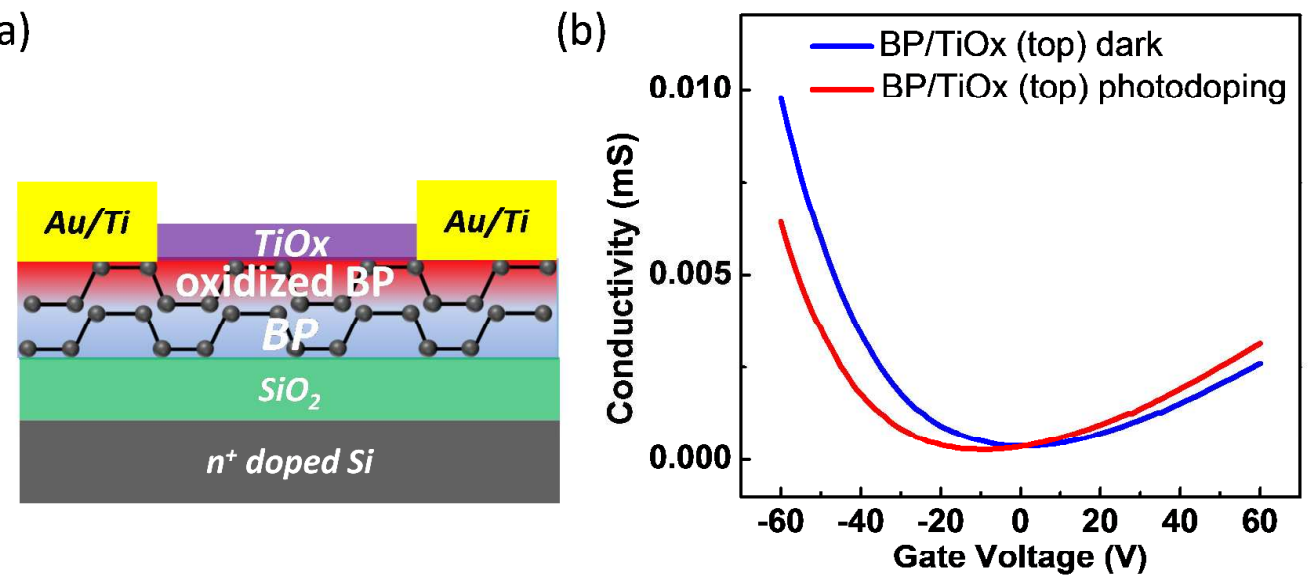

Figure S6 (a) Schematic image of a post-coated $\mathrm{TiO}_{\mathrm{x}} / \mathrm{BP}$ transistor. (b)

Gate-dependent characteristic curves of a post-coated $\mathrm{TiO}_{\mathrm{x}} / \mathrm{BP}$ transistor before and after photodoping.

\section{Band alignment of BP/TiOx heterostructure}

As shown in figure $\mathrm{S} 7(\mathrm{a})$, there is a large valence band position difference between the TiOx capping layer and $\mathrm{BP}$, which resulted in an energy barrier for hole conduction. Therefore, compared to the electron branch, a much higher voltage was required to turn on the device under p-type conduction as presented in Figure S7 (b). 
(a)

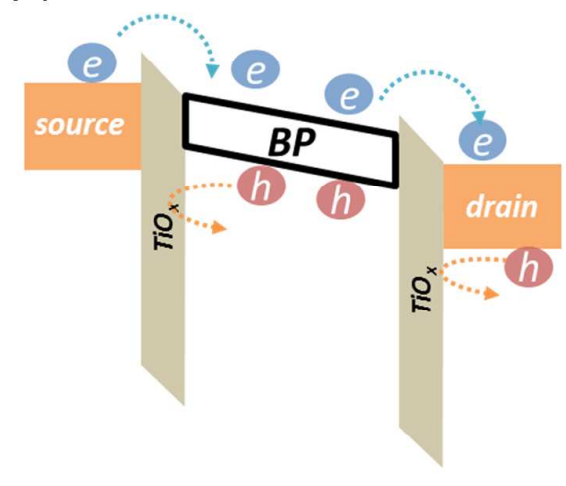

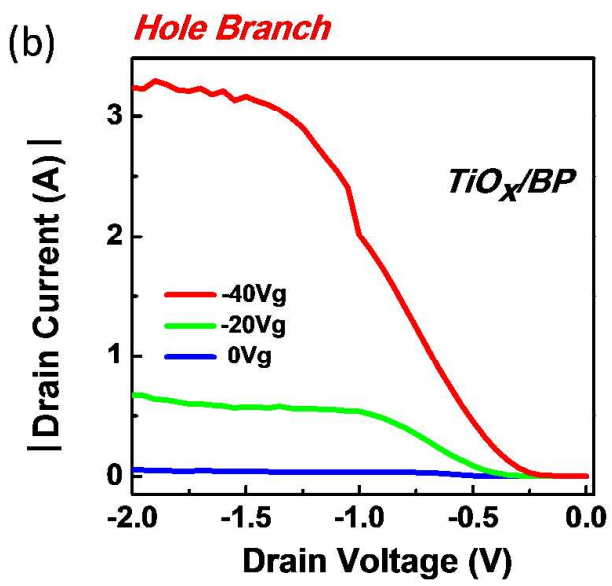

Figure S7. (a) Simiplied band alignment of TiOx/BP FET device. (b) Hole branch of the $\mathrm{I}-\mathrm{V}_{\mathrm{ds}}$ curve of TiOx/BP FET with extened drain voltages.

Hysteresis Curves of the TiOx/BP FET device.

Similar to other previous reports, current hysteresis were also observed in our BP FETs and TiOx/BP FETs with and without photo illumination, which may be related to the trap states as mentioned by the reviewer.

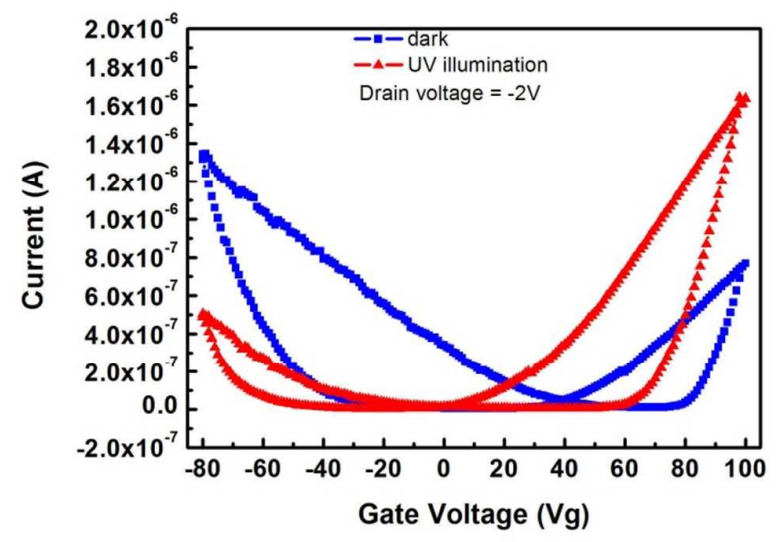

Figure S8. Cyclic scan of Vg of TiOx/BP FET. 


\section{A proposed device structure of BP p-n junction created by selectively light}

\section{illumination.}

An interesting concept of a proposed device structure with light illumination on a selective area to create a BP p-n junction could be feasible as shown in Figure S7, which may facilitate the future development of BP-based semiconductor logic devices and optoelectronic devices such as detectors or sensors.

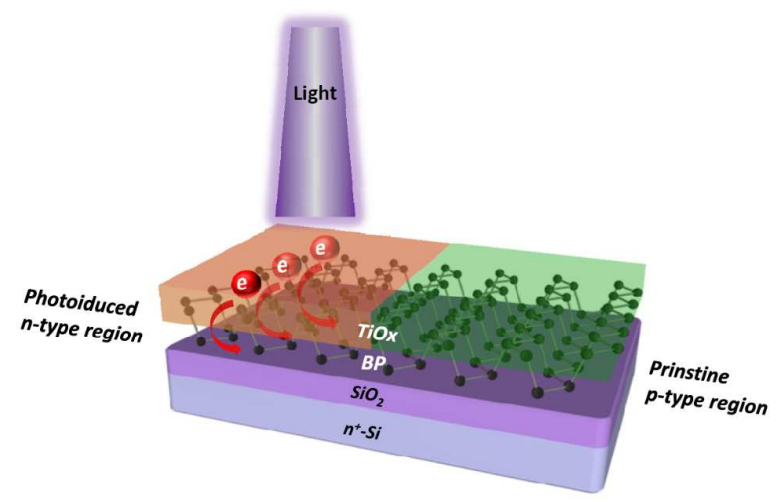

Figure S9 A proposed device structure of BP p-n junction created by selectively light illumination.

Reference

1. Li, L. et al. Black phosphorus field-effect transistors. Nat. Nanotechnol. 9, 372-377 (2014). 
2. Al-Ibrahim, M., Roth, H., Zhokhavets, U., Gobsch, G. \& Sensfuss, S. Flexible large area polymer solar cells based on poly (3-hexylthiophene)/fullerene. Sol. Energ. Mater. Sol. Cells 85, 13-20 (2005).

3. Tauc, J. Optical properties and electronic structure of amorphous Ge and $\mathrm{Si}$.

Mater. Res. Bull. 3, 37-46 (1968). 